\title{
Nutritional supplementation with the mushroom Agaricus sylvaticus reduces oxidative stress in children with HIV
}

\author{
Marcela S Figueira $\mathrm{MSc}^{1}$, Luana A Sá MSc ${ }^{1}$, Amanda S Vasconcelos DSc ${ }^{1}$, Danilo R Moreira DSc ${ }^{1}$, \\ Paula SOC Laurindo $\mathrm{MSc}^{1}$, Danielle RG Ribeiro BSc${ }^{1}$, Rogério S Santos $\mathrm{BSc}^{1}$, Paulo Guzzo MD², \\ Maria F Dolabela $\mathrm{PhD}^{3}$, Sandro Percario PhD DSc ${ }^{1}$
}

\begin{abstract}
MS Figueira, LA Sá, AS Vasconcelos, et al. Nutritional supplementation with the mushroom Agaricus sylvaticus reduces oxidative stress in children with HIV. Can J Infect Dis Med Microbiol 2014;25(5):257-264.
\end{abstract}

BACKGROUND: The involvement of free radicals and oxidative stress in HIV infection has been extensively studied, and the benefits of antioxidant supplementation in animal studies have been demonstrated. However, few studies have demonstrated a benefit in clinical studies.

OBJECTIVE: To verify the effects of dietary supplementation with Agaricus sylvaticus, a mushroom rich in antioxidants, on the oxidative profile of children born with HIV undergoing antiretroviral therapy. DESIGN: The sample included 24 children (both boys and girls) between two and eight years of age, of whom 10 were HIV positive and received supplementation with Agaricus sylvaticus for a three-month period, and 14 were HIV negative and received no supplementation. At the beginning and conclusion of the study, thiobarbituric acidreactive substances (TBARS), nitrite and nitrate (NN), Trolox equivalent antioxidant capacity, and the antioxidant capacity of inhibition of diphenyl-picrilhidrazil (DPPH) free radicals were analyzed. RESULTS: Before supplementation, significantly higher values of TBARS and NN, but decreased values of DPPH, were observed in infected subjects when compared with HIV-negative subjects. After supplementation, a reduction of TBARS and $\mathrm{NN}$ values and an increase in DPPH and Trolox equivalent antioxidant capacity values were observed in HIV-positive subjects.

CONCLUSIONS: The results of the present study suggest the involvement of oxidative stress in HIV infection, with the participation of NN synthesis. Additionally, supplementation reversed oxidative alterations and improved antioxidant defense in infected individuals, and may become a complementary strategy in the treatment of these patients.

Key Words: Agaricus sylvaticus; Antioxidants; Antiretroviral therapy; Children; HIV; Oxidative stress

IDS is a pandemic disease characterized by severe immunodefiA ciency in individuals infected with $\operatorname{HIV}(1,2)$. Highly active antiretroviral therapy (HAART) is the treatment of choice for HIVinfected patients (1).

HIV-infected individuals exhibit systemic oxidative stress (OS), one of the many important biochemical alterations in the infection progression, caused by the presence of free radicals and by decreases in molecules of the antioxidant system (3). OS is further increased by

\section{Des suppléments alimentaires contenant le champignon Agaricus sylvaticus renversent le stress oxydatif chez des enfants atteints du VIH}

HISTORIQUE : L'activité des radicaux libres et du stress oxydatif dans l'infection par le VIH a fait l'objet de nombreuses études, et les bienfaits des suppléments d'antioxydants ont été démontrés dans des études sur des animaux. Cependant, peu d'études en ont confirmé les avantages dans des études cliniques.

OBJECTIF : Vérifier les effets de suppléments alimentaires contenant de l'Agaricus sylvaticus, un champignon riche en antioxydants, sur le profil oxydatif des enfants nés avec le VIH sous thérapie antirétrovirale.

MÉTHODOLOGIE : L'échantillon se composait de 24 enfants (garçons et filles) de deux à huit ans, dont dix étaient positifs au VIH et ont reçu des suppléments d'Agaricus sylvaticus pendant trois mois, et 14 étaient négatifs au VIH est n'ont pas reçu de suppléments. Au début et à la fin de l'étude, les chercheurs ont analysé les substances réactives à l'acide thio-barbiturique (SRATB), les nitrites et les nitrates (NN), la capacité antioxydante en équivalent Trolox et la capacité antioxydante de l'inhibition des radicaux libres diphényl-picrylhydrazyl (DPPH)

RÉSULTATS : Avant la prise de suppléments, les sujets infectés présentaient des valeurs considérablement plus élevées de SRATB et de NN, mais plus faibles de DPPH, que les sujets négatifs au VIH. Après la prise de suppléments, les valeurs de SRATB et de NN diminuaient tandis que celles de DPPH et de la capacité antioxydante en équivalent Trolox augmentaient chez les sujets positifs au VIH.

CONCLUSIONS : D'après les résultats de la présente étude, le stress oxydatif est actif dans l'infection par le VIH, avec la participation de la synthèse des NN. De plus, des suppléments renversaient les altérations oxydatives et accroissaient la défense assurée par les antioxydants chez les sujets infectés. De tels suppléments pourraient devenir une stratégie complémentaire au traitement.

HAART, which plays an important role in determining the OS in these patients, aside from affecting their metabolic status (4).

In this context, lipid peroxidation is noteworthy because its byproducts, such as thiobarbituric acid-reactive substances (TBARS), have been found in high concentrations in HIV-infected individuals (5). Lipid peroxidation can be defined as a cascade of biochemical events resulting from the action of free radicals on unsaturated fatty acids in the cell membrane, leading to the destruction of its structure;

${ }^{1}$ Oxidative Stress Research Laboratory - Institute of Biological Sciences - Federal University of Para; ${ }^{2}$ Specialized Reference Unit for Maternal Eु

Adolescent Children (URE MIA); ${ }^{3}$ Pharmacy Faculty, Institute of Health Sciences, Federal University of Para - Belém, Pará, Brazil

Correspondence and reprints: Dr Sandro Percario, Laboratório de Pesquisas em Estresse Oxidativo, Instituto de Ciências Biológicas, Universidade Federal

do Pará, Av. Augusto Correa, n.1, Belém, Para, Brazil, 66075-110. Telephone 404-643-5248, fax 55-91-3201-7601, e-mail s.percario@bol.com.br

OPEN ACCESS

This open-access article is distributed under the terms of the Creative Commons Attribution Non-Commercial License (CC BY-NC) (http:// creativecommons.org/licenses/by-nc/4.0/), which permits reuse, distribution and reproduction of the article, provided that the original work is properly cited and the reuse is restricted to noncommercial purposes. For commercial reuse, contact support@pulsus.com 
TABLE 1

Characterization of the population studied

\begin{tabular}{lcccc}
\hline & & & \multicolumn{2}{c}{ Sex, $\mathbf{n}(\%)$} \\
\cline { 4 - 5 } Group & $\mathbf{n}(\%)$ & Age, years & Male & Female \\
\hline HIV+ & $10(41.7)$ & $3.7 \pm 2.0 \mathrm{~ns}$ & $3(30.0)$ & $7(70.0)$ \\
HIV- & $14(58.3)$ & $5.1 \pm 1.9$ & $12(85.7)$ & $2(14.3)$ \\
Total & $24(100)$ & & $15(62.5)$ & $9(37.5)$ \\
\hline
\end{tabular}

Values are expressed as mean $\pm S D$ unless otherwise indicated. HIV+ HIVinfected subjects supplemented with Agaricus sylvaticus; HIV- Negative controls; ns Nonsignificant versus HIV-

this impairs the selective permeability of the membrane, which regulates what enters and exits the cell (ie, allowing the uptake of nutrients and eliminating substances toxic to cells), thus facilitating the occurrence of intracellular damage with DNA alterations and low-density lipoprotein oxidation and, as a result, jeopardizing the integrity of extracellular matrix components (6).

Another important molecule in the oxidative processes is nitric oxide (NO), which acts as an inter- and intracellular signalling molecule in a variety of physiological and pathological functions. To date, the functions of this free radical are complex and antagonistic. It is considered to be a neurotransmitter and is also active in defending the body through antibacterial, antiparasitic and antiviral actions. In these cases, $\mathrm{NO}$ acts at higher concentrations than messenger concentrations and is toxic to invaders. The ability of $\mathrm{NO}$ to be beneficial or toxic depends on the tissue concentration and tissue clearance; the threshold of $\mathrm{NO}$ concentration between the toxicity required for defense action and nontoxicity to the host's cells is very small (6-9).

OS appears to play an important role in stimulating HIV replication and rapid progression of diseases with the development of immunodeficiency, which can cause cell damage and induce apoptosis, recognized as the main form of cell death of CD4+ T lymphocytes in HIV-infected individuals. This theory arose from numerous studies conducted on cell lines infected with HIV and patients infected with this virus $(5,10-16)$.

The generation of free radicals, physiological or otherwise, and their damage can be controlled by a normal endogenous antioxidant defense system, which requires an adequate intake of micronutrients with antioxidant activity (AOA) (10-11,17).

Important examples of endogenous antioxidants are the enzymes superoxide dismutase, catalase and glutathione peroxidase; the nonenzymatic endogenous antioxidants such as reduced glutathione (GSH), lipoic acid, albumin, ubiquinone (coenzyme Q10), metallothioneins, transferrin and ceruloplasmin; and the (especially dietary) nonenzymatic exogenous antioxidants, such as vitamin E, vitamin C, carotenoids and flavonoids, in addition to mineral nutrients such as zinc and selenium $(5,6)$.

Randomized studies have demonstrated the benefits of micronutrient supplementation, including the reduced risk of disease progression, especially for subjects in early stages of infection. Although the role of dietary antioxidant supplementation in the treatment of individuals who are already undergoing HAART has not been defined (18), several studies have demonstrated some benefits of antioxidant supplements in HIV patients. For example, Allard et al (19) supplemented HIV-positive patients with vitamins $\mathrm{E}$ and $\mathrm{C}$ for a three-month period and found a reduction in lipid peroxidation, according to TBARS levels, compared with the control group, showing that supplementation of these vitamins reduce OS during infection. Batterham et al (20) found that antioxidant supplementation in HIV-infected individuals promoted significant improvement in some measurements of the antioxidant defense such as selenium, GSH and glutathione peroxidase. In addition, Djohan et al (21) administered antioxidant nutrients from Alternanthera pungens herbal tea to asymptomatic HIV-positive patients and observed a meaningful reduction in the OS marker TBARS, as well as a significant increase in the number of CD4+ and CD8+ T cells, which can prevent the onset of opportunistic diseases.
TABLE 2

Characteristics of the antiretroviral therapy administered to subjects

\begin{tabular}{lc}
\hline Drug & $\mathbf{n}(\%)$ \\
\hline Current nucleoside reverse-transcriptase inhibitor & \\
Zidovudine (azidothymidine) & $10(100)$ \\
Lamivudine (3TC) & $10(100)$ \\
Didanosine & $1(10)$ \\
$\quad$ Tenofovir & $1(10)$ \\
Current protease inhibitor & \\
$\quad$ Darunavir & $1(10)$ \\
Ritonavir & $5(50)$ \\
Lopinavir & $4(40)$ \\
Current non-nucleoside reverse-transcriptase inhibitor & \\
$\quad$ Nevirapine & $3(30)$ \\
$\quad$ Efavirenz & $5(50)$ \\
Current integrase inhibitor & \\
Raltegravir & $1(10)$ \\
\hline
\end{tabular}

In this context, further studies are needed to elucidate the therapeutic and preventive role of micronutrients in the course of HIV infection as an adjunct to HAART $(12,22,23)$.

Mushrooms in the genus Agaricus (Agaricus bisporus, Agaricus blazei, Agaricus sylvaticus and others) have been widely studied on account of their medicinal properties, such as antitumour, immune system-boosting and antibacterial properties, among others (24-28). In extracts from this mushroom, we identified many molecules that have antioxidant properties, including vitamins $\mathrm{E}$ and $\mathrm{D}$, numerous carbohydrates, minerals and bioflavonoids; thus, there is a strong antioxidant potential when all of these molecules are conjugated in a single food such as in a mushroom (27). Additionally, some authors have demonstrated the benefit of the great antioxidant potential of $A$ sylvaticus in malaria $(29,30)$, colorectal cancer $(25)$ and atherosclerosis (31).

For that reason, it is of great interest to consider new treatment strategies associated with previously established antiretroviral therapy, which may slow disease progression and, thus, reduce the incidence of AIDS-related opportunistic complications, reduce mortality, increase survival and lead to a significant improvement in individuals' quality of life.

It is likely that supplementation with A sylvaticus, associated with HAART, may lead to reduced OS, and an improved antioxidant status and clinical condition in HIV-1 patients. Thus, the objective of the present study was to investigate the effects of supplementation containing the mushroom A sylvaticus on oxidative alterations and antioxidant defenses in children born with HIV undergoing antiretroviral therapy.

\section{METHODS}

The present experimental, prospective study involved children who were selected at the Specialized Reference Unit for Maternal \& Adolescent Children, a state-owned institution located in the city of Belém, Brazil, between two and eight years of age, of both sexes, who were HIV-1 positive (HIV+; n=10) and undergoing antiretroviral therapy. These subjects were compared with a second group of healthy children not infected with HIV-1 with comparable characteristics who did not receive the supplementation and formed the negative control group (HIV-, n=14; Table 1). All subjects in the HIV+ group were infected vertically (ie, born infected) and were taking HAART during the study period. The characteristics of HAART are presented in Table 2. Subjects in the HIV- group were relatives of subjects in the $\mathrm{HIV}+$ group in an attempt to ensure that their life conditions were as similar as possible to those of the HIV+ subjects.

The present study included all children $<10$ years of age, of both sexes, who were HIV+ and submitted to antiretroviral therapy, or 
TABLE 3

Nutritional information for Agaricus sylvaticus

\begin{tabular}{|c|c|c|c|}
\hline Nutrient & $\begin{array}{l}\text { Amount, } \\
\mathrm{mg} / 100 \mathrm{~g}\end{array}$ & Nutrient & $\begin{array}{c}\text { Amount, } \\
\mathrm{g} / 100 \mathrm{~g}\end{array}$ \\
\hline Sodium & 4.2 & Proteins & 39.4 \\
\hline Iron & 21.2 & Fats & 3.0 \\
\hline Calcium & 35.7 & Carbohydrates & 45.6 \\
\hline Potassium & 3.15 & Arginine & 1.71 \\
\hline Magnesium & 100 & Lysine & 1.55 \\
\hline Copper & 8.24 & Histidine & 0.62 \\
\hline Zinc & 6.61 & Phenylalanine & 1.11 \\
\hline Manganese & 0.65 & Tyrosine & 0.83 \\
\hline Selenium & 0.036 & Leucine & 1.72 \\
\hline Thiamine $\left(\mathrm{B}_{1}\right)$ & 1.21 & Isoleucine & 1.10 \\
\hline Riboflavin $\left(\mathrm{B}_{2}\right)$ & 3.41 & Methionine & 0.39 \\
\hline Vitamin $B_{6}$ & 0.83 & Valine & 1.28 \\
\hline Vitamin $\mathrm{B}_{12}$ & 0.00017 & Alanine & 1.75 \\
\hline Vitamin C & 56.0 & Glycine & 1.25 \\
\hline Calciferol & 0.0058 & Proline & 1.26 \\
\hline Folic acid & 0.36 & Glutamic acid & 5.73 \\
\hline Pantothenic acid & 39.4 & Serina & 1.20 \\
\hline Inositol & 201 & Threonine & 1.21 \\
\hline Niacin & 39.9 & Aspartic acid & 2.35 \\
\hline Phenols & 0.10 & Tryptophan & 0.43 \\
\hline Beta d-glucan & 127 & Cistine & 0.36 \\
\hline Isoflavones (genistein) & 0.88 & & \\
\hline
\end{tabular}

HIV - children, residents of the metropolitan area of Belém (Pará, Brazil), who attended to the Specialized Reference Unit for Maternal $\&$ Adolescent Children seeking treatment or accompanying patients during the study period and whose parents and/or guardians agreed to participate by signing the consent form. Exclusion criteria included: taking any kind of supplementation of antioxidant nutrients such as multivitamins and/or polyminerals; having other associated diseases such as diabetes, hypertension and cancer; and children whose parents and/or guardians refused to participate.

Supplementation was achieved over a consecutive three-month period. To administer A sylvaticus, a commercially produced syrup formulation of this mushroom (Cogumelo do Sol Agaricus do Brasil LTDA, Brazil) was used, for which the formula is standardized and registered as food by the Brazil's Ministry of Health (Registration No. 6.1021.0002.001-7). The nutritional composition of this syrup is presented in Table 3. Each millilitre of syrup provides $300 \mathrm{mg}$ of A sylvaticus. Dosages were adjusted according to the subjects' body weight (Table 4) to provide an average dose of $30 \mathrm{mg}$ of mushroom per kilogram of body weight per day. Subjects were instructed to take the supplements as a single dose early in the morning with breakfast. On the same day the protocol started and before receiving the supplements, a peripheral blood sample was collected for biochemical assay (TO). Supplements were taken for 90 consecutive days and, in the morning of the following day, another blood sample was collected (T3). The procedures were conducted in a double-blinded manner, in which blood collection, laboratory testing and supplementation administration were performed by different researchers.

During the supplementation period, all subjects were instructed to avoid antioxidant supplements of any kind, and to maintain their regular food intake as usual. Daily food intake was recorded and antioxidant content was assessed to identify any discrepancies among individuals. If significant modification to the antioxidant content of the diet was detected, data from the subject were not included.

Sample preparation and storage

At the beginning (TO) and on the day immediately following the supplementation period (90 days [T3]), peripheral blood samples were collected for the analysis of OS and antioxidant defense markers:
TABLE 4

Dosages of mushroom Agaricus sylvaticus (syrup), according to body weight of subjects

\begin{tabular}{lcc}
\hline Body weight, $\mathbf{k g}$ & Daily doses, $\mathbf{~ L L}$ & A sylvaticus, $\mathbf{g}$ \\
\hline$<10$ & 1 & 0.30 \\
$11-20$ & 2 & 0.60 \\
$21-30$ & 3 & 0.90 \\
$31-40$ & 4 & 1.20 \\
$>40$ & 5 & 1.50 \\
\hline
\end{tabular}

TBARS, nitrite and nitrate (NN) (stable metabolites of NO), Trolox equivalent antioxidant capacity (TEAC) and antioxidant capacity measured by reduction of the diphenyl-picrylhydrazyl radical (DPPH). For the subjects in HIV- group, only one blood sample was collected for laboratory testing at baseline. Samples were collected in properly identified tubes containing anticoagulant (EDTA). The tubes were centrifuged at $2500 \mathrm{rpm}$ for $15 \mathrm{~min}$; plasma was ready for use on being separated in a container ( $1.5 \mathrm{~mL}$ microcentrifuge tube) labelled according to the identification protocol of subjects, frozen at $-20^{\circ} \mathrm{C}$. The samples were thawed at room temperature for measurement and assayed in the same batch.

\section{Laboratory evaluation of OS and antioxidant defense}

All laboratory tests were performed in triplicates at a maximum acceptance of $5 \%$ variance. Every assay was performed with a standard curve and proper quality controls were assayed with the samples.

TBARS: Lipid peroxidation was determined using the TBARS assay, performed according to the method proposed by Kohn and Liversedge (32) and modified by Percário et al (33), which is based on the reaction of two molecules of thiobarbituric acid (TBA) with one molecule of malondialdehyde, at low $\mathrm{pH}$ (2.5) and high temperature to form TBA-malondialdehyde-TBA, a pink complex with a maximum absorption at $535 \mathrm{~nm}$. The technical procedure involved the addition of $500 \mu \mathrm{L}$ of the sample to $1.0 \mathrm{~mL}$ of TBA reagent $(10 \mathrm{mM}$ TBA dissolved in $75 \mathrm{mM} \mathrm{KH}_{2} \mathrm{PO}_{4}$ ). Next, the mixture was placed in a water bath $\left(95^{\circ} \mathrm{C}\right)$ for $60 \mathrm{~min}$ and, after incubation, was allowed to cool at room temperature; $4.0 \mathrm{~mL}$ of $\mathrm{n}$-butyl alcohol was then added, homogenized with a vortex mixer and centrifuged at $2500 \mathrm{rpm}$ for $15 \mathrm{~min}$; $3.0 \mathrm{~mL}$ was collected from the supernatant and absorption was measured spectrophotometrically at $535 \mathrm{~nm}$ (FEMTO, Brazil).

NN: The measurements of NN were performed using the Total NO/ Nitrite/Nitrate Assay Kit (KGE001; R\&D Systems, USA). NO undergoes a series of reactions with several different molecules, producing nitrate $\left(\mathrm{NO}_{3}^{-}\right)$and nitrite $\left(\mathrm{NO}_{2}{ }^{-}\right)$. The measurement of these products is conducted using the spectrophotometric method, with ELISA plates as support, in which the use of nitrate reductase promotes the conversion of nitrate to nitrite. Thereafter, the Griess reagent converts nitrite into a deep purple-coloured azo compound with an absorbance maximum at $540 \mathrm{~nm}$. Additionally, to minimize interference produced by the Griess reagent by NADPH (cofactor of the enzyme NO synthase), a combination of small amounts of NADPH was made using a reducing catalytic system, preventing the oxidation of the NADPH to $\mathrm{NADP}^{+}$. The prepared plate was covered and incubated for $30 \mathrm{~min}$ at $37^{\circ} \mathrm{C}$. On completion of the incubation period, Griess reagents I and II were added and $10 \mathrm{~min}$ was allowed for the colour to develop, which was followed by measurement of the absorbance at $540 \mathrm{~nm}$ (PerkinElmer, Victor X3).

TEAC: The antioxidant potential was determined according to its equivalence to a potent antioxidant known as Trolox (6-hydroxy2,5,7,8-tetrameticromono-2-carboxylic acid; 23881-3, Aldrich Chemical Company, USA), a synthetic, water-soluble analogue of vitamin E. The method proposed by Miller et al (34), modified by Re et al (35), was followed at adapted conditions of temperature, relative proportions of reagents and measurement time. Briefly, it is a colourimetric technique based on a reaction between 2,2-azinobis3-ethylbenzothiazoline-6-sulfonic acid diammonium (ABTS) and 


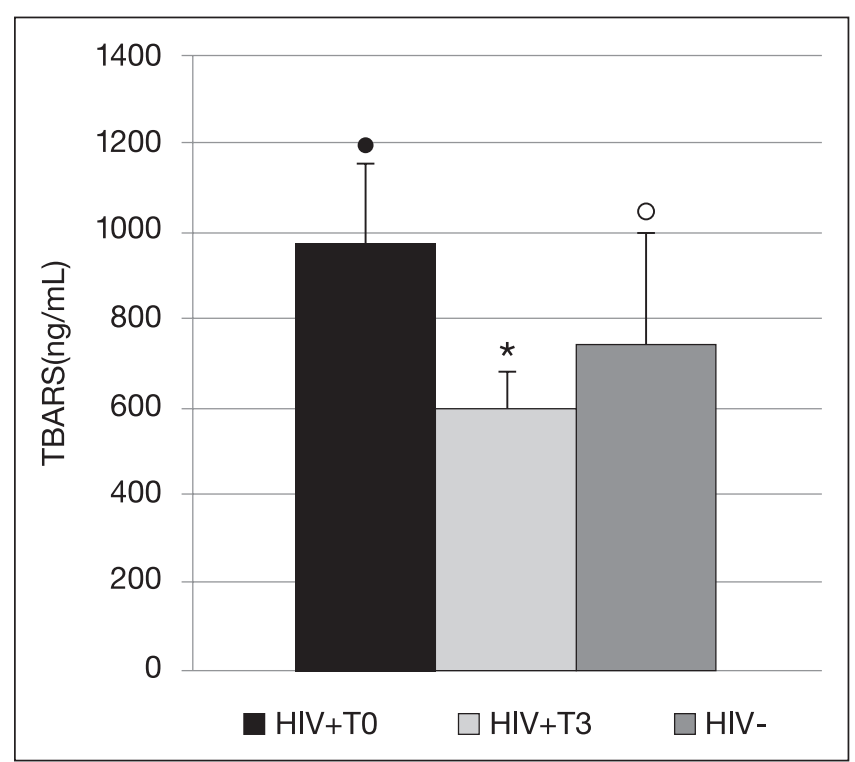

Figure 1) Thiobarbituric acid-reactive substances (TBARS) in HIVinfected children before supplementation with Agaricus sylvaticus (HIV+ TO), after three months of supplementation (HIV+T3) and in noninfected and nonsupplemented controls (HIV-). $\bullet P=0.0385$ versus HIV-; $* P=0.0021$ versus $\mathrm{HIV}+\mathrm{TO} ;{ }^{\circ} \mathrm{P}=0.0322$ versus $\mathrm{HIV}+\mathrm{T} 3$

$\mathrm{K}_{2} \mathrm{~S}_{2} \mathrm{O}_{8}$, directly producing radical cation ABTS+, a chromosphore of green/blue colour with maximum absorbance at $734 \mathrm{~nm}$. The addition of antioxidants to this preformed radical cation reduces it, once again, to ABTS, with the extent and time scale being dependent on antioxidant capacity, concentration of the antioxidants and duration of the reaction. This can be measured using spectrophotometry to observe the change in the absorbance at $734 \mathrm{~nm}$ over $5 \mathrm{~min}$. Thus, the extent of discolouration as an index of inhibition of the radical cation ABTS+ is determined as the total AOA of the sample, and its relationship with Trolox reactivity is subsequently calculated under the same conditions. The final results are expressed in $\mathrm{mmol} / \mathrm{L}$, corresponding to the Trolox concentration with antioxidant capacity equivalent to the analyzed sample.

Antioxidant capacity according to DPPH radical reduction: The antioxidant capacity was determined by reduction of the DPPH radical. The DPPH radical has a deep violet colour in solution, with strong absorption at $515 \mathrm{~nm}$ to $517 \mathrm{~nm}$. The method proposed by Blois (36) was adapted, in which the AOA of a given substance is measured through interaction with DPPH, resulting in the irreversible formation of hydrogenated product (hydrazine), which is colourless. The AOA of the sample is expressed in terms of its ability to cause a reduction in the absorption of a DPPH solution at a given concentration. For this experiment, a solution of DPPH in $0.1 \mathrm{mM}$ ethanol was prepared. In each tube, $600 \mathrm{~mL}$ of $0.1 \mathrm{mM}$ DPPH solution in ethanol, $50 \mu \mathrm{L}$ of sample and $350 \mathrm{~mL}$ of distilled water was added, to result in a final volume of $1 \mathrm{~mL}$. After a period of $30 \mathrm{~min}$ in a water bath at $37^{\circ} \mathrm{C}$, absorbance was measured at $517 \mathrm{~nm}$. The initial absorbance of the DPPH solution was measured, and the changes observed in absorbance were proportional to the sample AOA. As in TEAC, a Trolox standard curve was used. The samples were deproteinized using $2 \mathrm{~mL}$ of trichloroacetic acid at $10 \%$ per millilitre of plasma (1:3); after homogenization in vortex, samples rested for $10 \mathrm{~min}$ and were centrifuged for $10 \mathrm{~min}$, and the supernatant was collected. This supernatant was diluted in $0.9 \% \mathrm{NaCl}$ (1:2). The absorbance values obtained were subtracted from the initial DPPH absorbance; concentrations were obtained from the equation of the Trolox standard curve and values were multiplied by the dilution factor of six.

\section{Ethical aspects}

The project was previously reviewed and approved by the Research Ethics Committee of the Health and Sciences Institute of the Federal University of Para (report 024/09 CEP-ICS/UFPA). Parents and/or guardians of study subjects signed written informed consent, authorizing participation in the research, in full accordance with the precepts of ethics on research with humans and with the precepts established in the Brazilian legislation (37).

\section{Statistical analysis}

For each parameter, an analysis of possible outlier values was performed, which uses the interquartile range in the calculation (ie, the difference between the third quartile $\left[Q_{3}\right]$ and the first quartile $\left[Q_{1}\right]$ ), referred to as $d_{j}$. All values less than $Q_{1}-3 / 2 d_{j}$ or greater than $Q_{3}+$ $3 / 2 d_{j}$ were considered to be discrepant and were not included in the statistical calculations.

The statistical analysis was initially performed using the Kolmogorov-Smirnov normality test to verify whether the sample showed normal distribution; SPSS version 17.0 (IBM Corporation, USA) was used. Differences between initial and final values (before and after three months of supplementation) of the HIV+ group for each parameter were assessed using the paired Student's $t$ test. Differences between groups (initial HIV+ versus HIV- and final HIV+ versus HIV-) were assessed using the nonpaired Student's $t$ test.

To verify any possible correlation between parameters, the Pearson correlation test was performed, considering the paired values of two parameters obtained for one subject. The following meanings were considered for correlation coefficients $(r):-1.00$, perfect negative correlation; -0.95 , strong negative correlation; -0.50 , moderate negative correlation; -0.10 , weak negative correlation; 0.00 , no correlation; +0.10 , weak positive correlation; +0.50 , moderate positive correlation; +0.95 , strong positive correlation; and +1.00 , perfect positive correlation.

The statistical analysis was performed using BioEstat 5.0 (38). Differences were considered to be statistically significant at $\mathrm{P}<0.05$ for all tests.

\section{RESULTS}

The assessed population consisted of 24 subjects, predominantly male $(62.5 \%)$. Characteristics of the study population are summarized in Table 1.

\section{TBARS concentrations}

The mean concentration of TBARS in the HIV+ group before supplementation was significantly higher than in the HIV- group (HIV+, $967 \pm 191 \mathrm{ng} / \mathrm{mL}$; HIV-, $742 \pm 262 \mathrm{ng} / \mathrm{mL} ; \mathrm{P}=0.038)$. After three months, the mean value of the group supplemented with A sylvaticus was significantly reduced $(516 \pm 168 \mathrm{ng} / \mathrm{mL} ; 46.6 \%$ reduction, $\mathrm{P}=0.0021$ ). Figure 1 shows the behaviour of TBARS before and after supplementation with A sylvaticus.

\section{NN}

The mean NN concentration in the HIV+ group before supplementation was significantly higher than in the HIV- group (HIV+, $75.2 \pm 32.7 \mu \mathrm{mol} / \mathrm{L} ; \mathrm{HIV}-, 27.4 \pm 4.83 \mu \mathrm{mol} / \mathrm{L} ; \mathrm{P}=0.0013)$. After three months, the mean value of the supplemented group with A sylvaticus was significantly reduced $(48.3 \pm 10.3 \mu \mathrm{mol} / \mathrm{L} ; 35.7 \%$ reduction, $\mathrm{P}=0.020$ ). Figure 2 presents $\mathrm{NN}$ measurements before and after supplementation with A sylvaticus.

\section{TEAC}

The mean TEAC value in the HIV+ group before supplementation was not different compared with the HIV- group (HIV+, $3.43 \pm 0.13 \mathrm{mmol} / \mathrm{L} ; \mathrm{HIV}-, 3.44 \pm 0.10 \mathrm{mmol} / \mathrm{L} ; \mathrm{P}=0.786$ ). However, after three months, the mean value of the group supplemented with A sylvaticus showed a significant increase $(3.61 \pm 0.12 \mathrm{mmol} / \mathrm{L}$, a $5.24 \%$ increase; $\mathrm{P}=0.0105)$. Figure 3 shows the TEAC measurements before and after supplementation with A sylvaticus. 


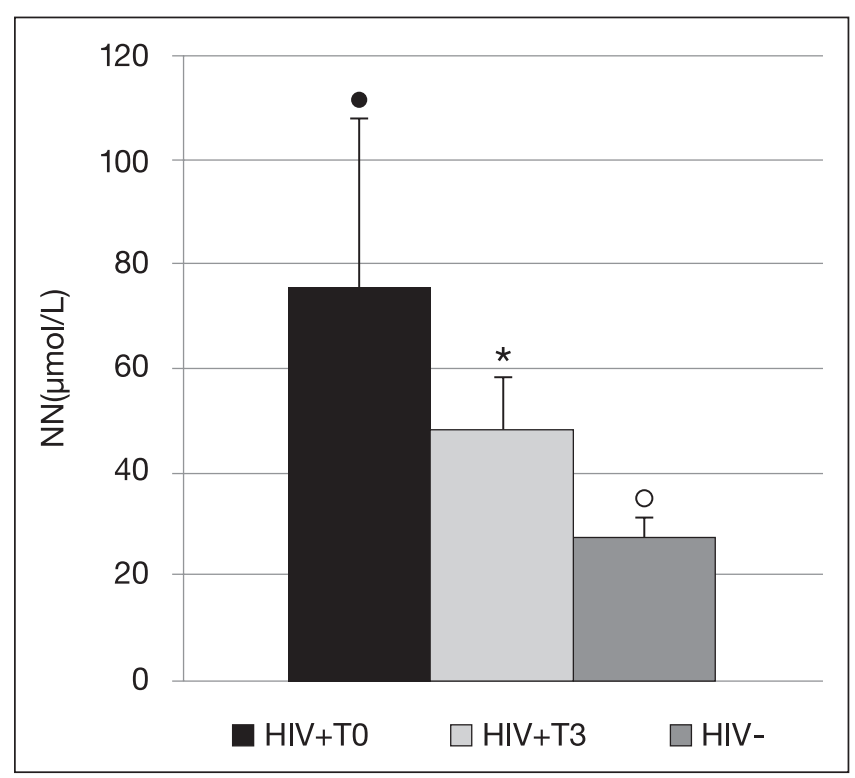

Figure 2) Nitrites and nitrates (NN) in HIV-infected children before supplementation with Agaricus sylvaticus (HIV+ TO), after three months of supplementation (HIV+T3), and in noninfected and nonsupplemented controls $(\mathrm{HIV}-) . \bullet P=0.0013$ versus $\mathrm{HIV}-;{ }^{*} \mathrm{P}=0.0208$ versus $\mathrm{HIV}+$ T0; ${ }^{\circ} \mathrm{P}<0.0001$ versus HIV $+\mathrm{T} 3$

Antioxidant capacity according to DPPH radical reduction The mean DPPH level in the HIV+ group before supplementation was significantly lower than in the HIV- group (HIV+, 2.76 $\pm 0.12 \mathrm{mmol} / \mathrm{L}$; HIV-, $4.42 \pm 0.20 \mathrm{mmol} / \mathrm{L} ; \mathrm{P}<0.0001)$. After three months, the mean value of the group supplemented with $A$ sylvaticus increased significantly $(4.01 \pm 0.11 \mathrm{mmol} / \mathrm{L}$; a $45.3 \%$ increase, $\mathrm{P}<0.0001)$. Figure 4 shows the DPPH measurements before and after supplementation with A sylvaticus.

\section{Correlation studies}

To better understand the behaviour of the variables assayed in the present study, correlation studies were performed. First, TBARS concentrations and TEAC values were correlated. A highly significant moderate negative correlation $(\mathrm{r}=-0.5183, \mathrm{P}=0.0047)$ was observed for the HIV+ group, demonstrating that as TEAC increases, TBARS concentration decreases. In the HIV- group, there was no correlation between these variables $(r=-0.0032 ; \mathrm{P}=0.9914)$. Correlations and analyses of statistical significance are presented in Figure 5.

TBARS and DPPH measurements were also correlated, a moderate negative correlation with high statistical significance $(\mathrm{r}=-0.5972$, $\mathrm{P}=0.0054$ ) in the HIV+ group, demonstrating that as DPPH values increase, TBARS concentrations decrease. In the HIV- group, there was no meaningful correlation between the variables considered $(r=0.0502 ; \mathrm{P}=0.8647)$. Correlations and their statistical significance analysis are shown in Figure 6.

All correlations involving $\mathrm{NN}$ were not statistically significant.

\section{DISCUSSION}

Before supplementation, the TBARS concentration values in the HIV+ group were observed to be significantly higher than in the HIV - group. These findings support the involvement of OS in the course of HIV infection, because it shows that this infection elevated lipid peroxidation to the highest levels in these subjects. These data are consistent with the literature, considering that studies have presented high TBARS values in infected adults $(14,39)$ and even in children (40). Additionally, after three months of supplementation with A sylvaticus, TBARS mean values decreased substantially, demonstrating that supplementation can reduce the OS caused by HIV infection.

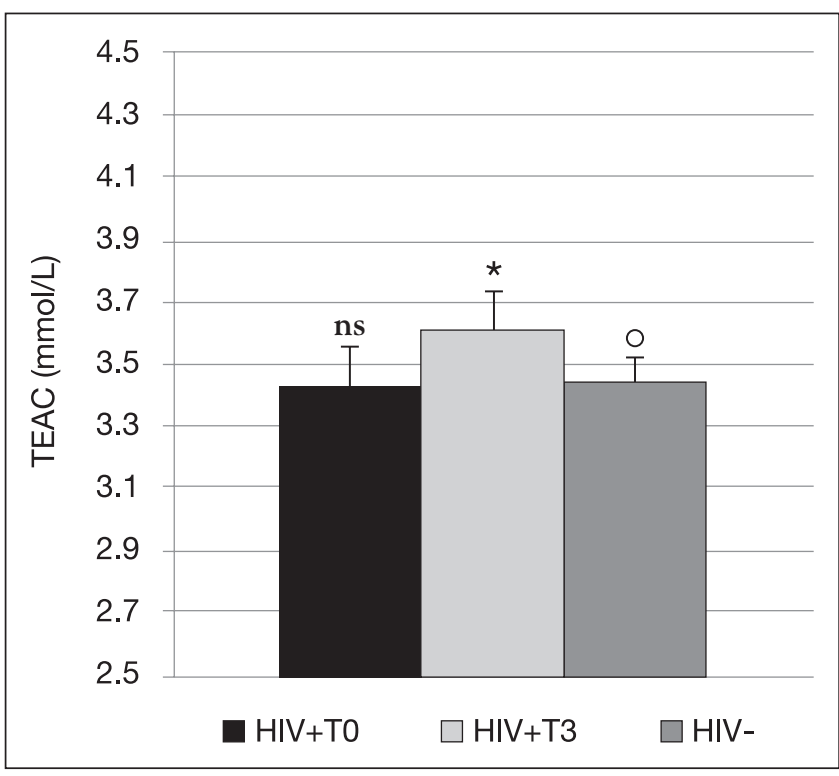

Figure 3) Trolox equivalent antioxidant capacity (TEAC) in HIVinfected children before supplementation with Agaricus sylvaticus (HIV+ TO), after three months of supplementation (HIV+ T3), and in noninfected and nonsupplemented controls (HIV-). ns Nonsignificant versus HIV-; $* P=0.0105$ versus $\mathrm{HIV}+\mathrm{TO} ;{ }^{\circ} \mathrm{P}=0.0016$ versus $\mathrm{HIV}+\mathrm{T} 3$

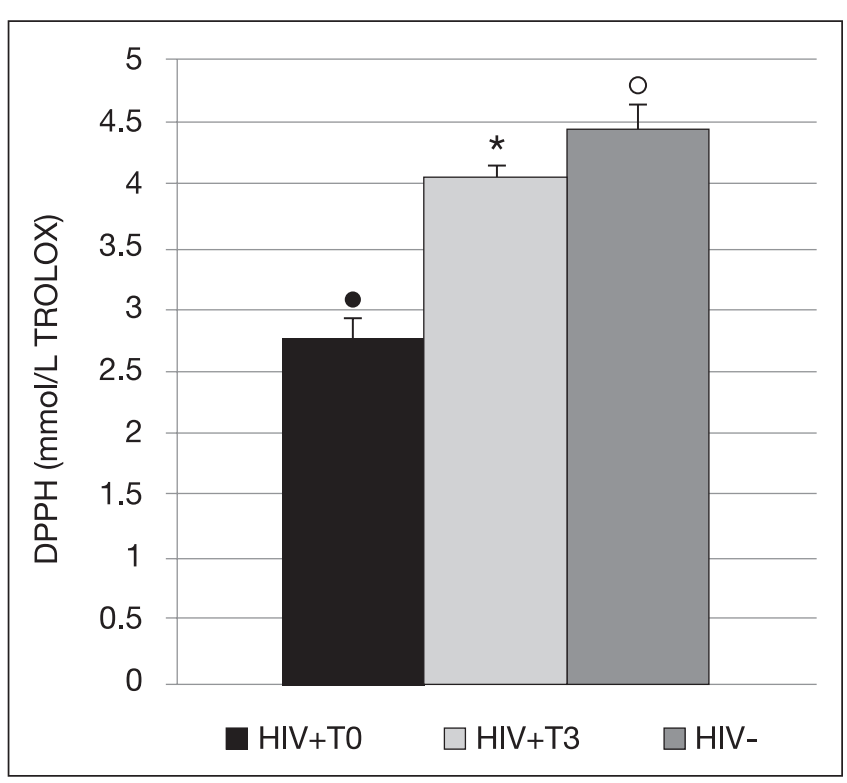

Figure 4) Antioxidant capacity by diphenyl-picrylhydrazyl radical (DPPH) reduction in HIV-infected children before supplementation with Agaricus sylvaticus (HIV+ TO), after three months of supplementation $(\mathrm{HIV}+\mathrm{T} 3)$, and in noninfected and nonsupplemented controls (HIV-). $\bullet P<0.0001$ versus HIV-; $* P<0.0001$ versus HIV+ T0; ${ }^{\circ} \mathrm{P}<0.0001$ versus $H I V+T 3$

When analyzing the changes in NO caused by HIV infection, the mean values in the HIV group before supplementation were significantly higher than in the HIV- group, similar to the changes observed in TBARS. Although the production of $\mathrm{NO}$ was intimately associated with OS observed during infection, this molecule is also considered to be an important component of the host immune response in many viral infections including retrovirus infections $(9,41)$.

Moreover, in some cases, the production of $\mathrm{NO}$ during infectious diseases may have deleterious effects, a fact particularly important for 

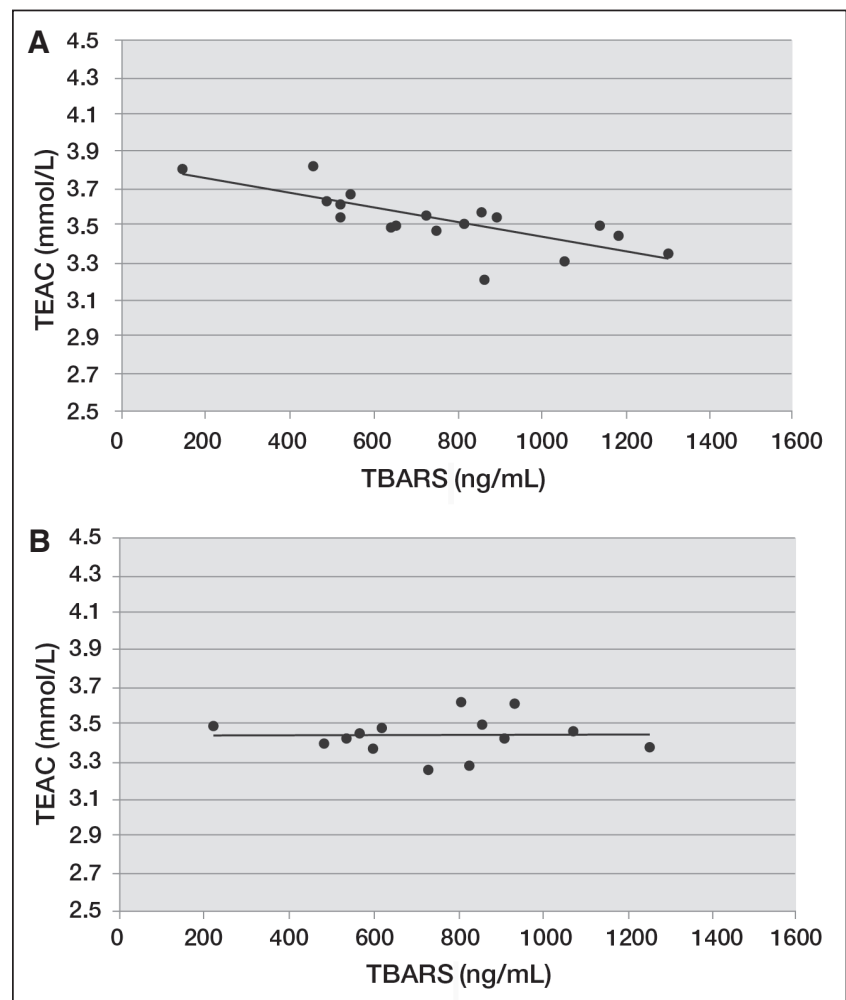

Figure 5) Correlation between thiobarbituric acid-reactive substances (TBARS) and Trolox equivalent antioxidant capacity (TEAC) of serum samples from HIV-infected children. A HIV-infected patients supplemented with Agaricus sylvaticus $(r=-0.5183, P=0.0047)$; B Negative controls $(r=-0.0032$ and $P=0.9914)$

HIV infection, where NO may contribute to the pathogenesis of AIDS. NO production by human monocytes and macrophages may rely on the induction of expression of the enzyme NO synthase by proinflammatory cytokines, which, in turn, are induced in response to HIV infection. It has also been shown that there is a positive correlation between $\mathrm{NO}$ production and viral load, suggesting that HIV may induce $\mathrm{NO}$ synthesis in vivo, particularly in patients with neurological complications $(7,41)$.

However, existing results regarding $\mathrm{NO}$ performance during HIV infection are contradictory, and whether NO synthesis is a virus inhibitory factor or inducer of viral replication is not clearly established $(9,41,42)$.

Similar to the TBARS values, the mean $\mathrm{NN}$ values showed important reduction after supplementation, suggesting that antioxidation is an inhibitory factor of $\mathrm{NO}$ synthesis.

The OS observed by the increased concentration of TBARS and $\mathrm{NN}$ resulting from HIV infection can be controlled by the antioxidant defense system. Therefore, in addition to OS markers, the antioxidant capacity of infected subjects was evaluated.

This antioxidant capacity was evaluated by its equivalence to Trolox, a potent synthetic antioxidant analogous to vitamin E. Notably, the mean values of TEAC in the HIV+ group before supplementation showed no statistically significant differences when compared with the HIV- group. However, the antioxidant capacity of subjects was also evaluated by DPPH reduction. The results obtained in the HIV+ group before supplementation were significantly lower than in the HIV - group, showing a reduced antioxidant capacity on account of HIV infection. In the literature, there are no studies evaluating the antioxidant capacity according to DPPH reduction during HIV infection, but several studies have demonstrated decreased antioxidant capacity in these subjects $(39,43,44)$.

The reduction of total antioxidant capacity can be explained by the reduced activity of antioxidant enzymes. In later stages of the
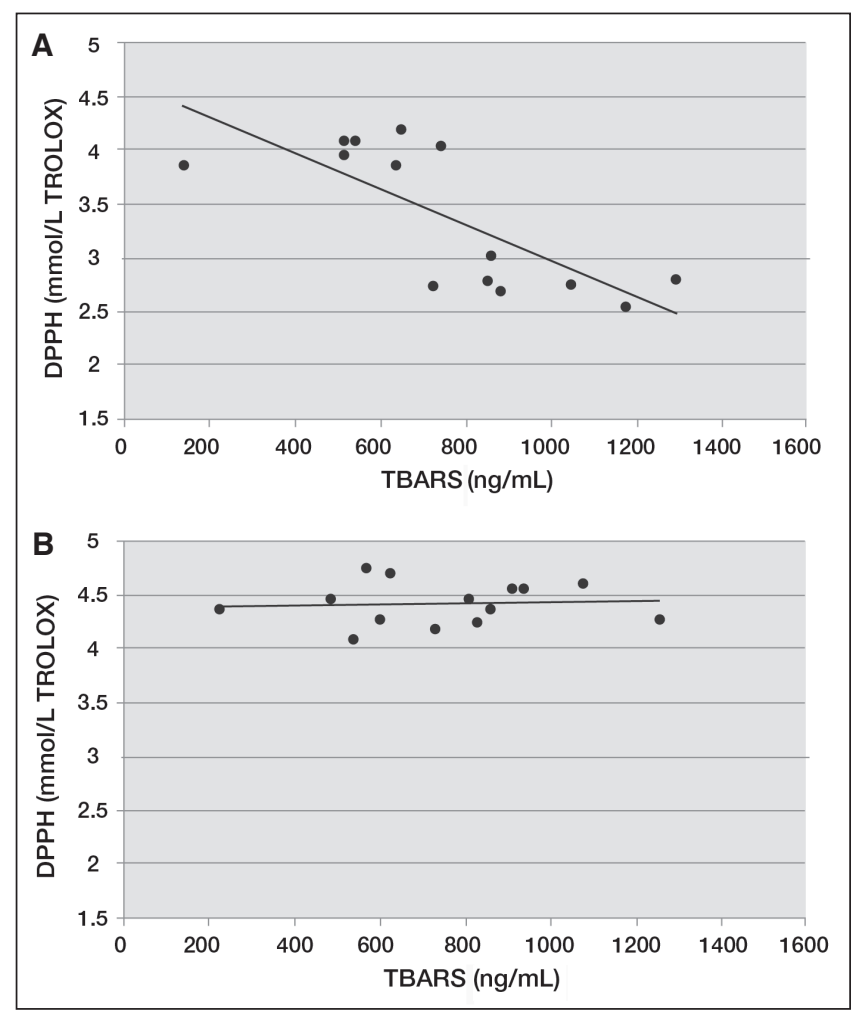

Figure 6) Correlation between thiobarbituric acid-reactive substances (TBARS) and antioxidant capacity according to diphenyl-picrilhidrazil radical (DPPH) reduction of serum samples from HIV-infected children. A HIV-infected patients supplemented with Agaricus sylvaticus ( $r=-0.5972$, $P=0.0054) ; B$ Negative controls $(r=0.0502, P=0.8647)$

disease, glutathione peroxidase activity is low, which can be explained by the fact that its activity increases primarily after lipid peroxidation by an adaptive response similar to that of superoxide dismutase, and then is reduced as a result of consumption of its cofactors. This may lead to a worsening of the disease as opportunistic infections appear along with increased production of reactive oxygen/nitrogen species (45). However, it is noteworthy that the subjects of the present study were not in such late disease conditions; rather, they had controlled HIV/AIDS and, thus, the present study demonstrated that a decrease in antioxidant capacity in HIV+ patients can be reduced even before its latter stages.

Additionally, HIV progressively depletes GSH in humans. Despite accumulated evidence suggesting the role of reduced GSH in the pathogenesis of HIV, controversies remain about the mechanism of this depletion, especially in trying to develop appropriate therapeutic strategies to help compensate for reduced antioxidant capacity (46).

The reduction of antioxidant capacity may also be explained by the decrease of molecules such as zinc, selenium, vitamin E and carotenes, which are part of the exogenous enzymatic antioxidant system, featuring a deficiency of micronutrients markedly severe in these patients $(47-49)$. However, it is important to note that the concentrations of these molecules were not evaluated in the present study.

According to Buys et al (50), micronutrients play a role in the pathogenesis of HIV. Children and adults infected with HIV exhibit deficiencies in several micronutrients resulting from malnutrition that accompanies the advance of the disease. These deficiencies appear to contribute to immune dysfunction, morbidity of infections and, consequently, to disease progression.

Selenium deficiency has been shown to be a significant predictor of HIV-related mortality. Despite the fact that this deficiency is relatively rare in healthy humans, a considerable number of studies have demonstrated a reduction in plasma concentrations of selenium and glutathione peroxidase activity in subjects with HIV/AIDS, which 
may result from the occurrence of absorptive defects in patients with the disease (51).

Additionally, HAART treatment may be responsible for part of the reduction in the antioxidant capacity of subjects as well as for the increase in oxidant molecules in those patients. In this sense, a recent study showed that, compared with control subjects, HIV-1 infected patients treated with HAART exhibited high levels of OS, in parallel with decreased levels of total AOA (4), results similar to the present findings.

In the present study, TEAC mean values increased considerably after supplementation with A sylvaticus. In relation to DPPH, similar behaviour was noted. Recent studies have demonstrated the beneficial effects of supplemental antioxidant nutrients in the course of HIV infection. Suttajit (15) reported that nutritional interventions may improve the nutritional status and maintain the immune system. Moreover, high doses of specific vitamins, minerals and synthetic antioxidants have been proposed to protect or reduce OS induced by reactive oxygen and

\section{REFERENCES}

1. Peçanha EP, Antunes OAC, Tanuri A. Estratégias farmacológicas para a terapia anti-AIDS. Quim Nova 2002;25:1108-16.

2. Bricarello LP, Lopes HV, Bricarello SGA. Terapia nutricional na síndrome de imunodeficiência adquirida. In: Silva SMCS, Mura JDP eds. Tratado de alimentação, nutrição e dietoterapia. São Paulo: Roca, 2007:583-9.

3. Nakamura H, Masutani H, Yodoi J. Redox imbalance and its control in HIV infection. Antioxid Redox Signal 2002;4:455-64.

4. Mandas A, Iorio EL, Congiu MG, et al. Oxidative imbalance in HIV-1 infected patients treated with antiretroviral therapy. J Biomed Biotechnol Id 2009;749575:7.

5. Pace GW, Leaf CD. The role of oxidative stress in HIV disease. Free Radic Biol Med 1995;19:523-28.

6. Halliwell B, Gutteridge JM. Free radicals in Biology and Medicine. Oxford: Oxford University Press; 2007.

7. Jiménez JL, González-Nicolás J, Alvarez S, Fresno M, MuñozFernández MA. Regulation of human immunodeficiency virus type 1 replication in human $\mathrm{T}$ lymphocytes by nitric oxide. J Virol 2001;75:4655-63.

8. Benz D, Cadet P, Mantione K, Zhu W, Stefano G. Tonal nitric oxide and health: Anti-bacterial and-viral actions and implications for HIV. Med Sci Monit 2002;8:27-31.

9. Cairoli E, Scott-Algara D, Pritsch O, Dighiero G, Cayota A. HIV-1 induced decrease of nitric oxide production and inducible nitric oxide synthase expression during in vivo and in vitro infection. Clin Immunol 2008;127:26-33.

10. Allard JP, Aghdassi E, Chau J, Salit I, Walmsley S. Oxidative stress and plasma antioxidant micronutrients in humans with HIV infection. Am J Clin Nutr 1998;67:143-7.

11. Kotler DP. Antioxidant therapy and HIV infection: 1998. Am J Clin Nutr 1998;67:7-9.

12. Marston B, De Cock KM. Multivitamins, nutrition, and antiretroviral therapy for HIV disease in Africa. N Engl J Med 2004;351:78-80.

13. Rabaud C, Tronel H, Fremont S, May T, Canton P, Nicolas JP. Free radicals and HIV infection. Ann Biol Clin 1997;55:565-71.

14. Suresh DR, Annam V, Pratibha K, Prasad BVM. Total antioxidant capacity - a novel early bio-chemical marker of oxidative stress in HIV infected individuals. J Biomed Sci 2009;16:61.

15. Suttajit M. Advances in nutrition support for quality of life in HIV+/AIDS. Asia Pac J Clin Nutr 2007:16:318-22.

16. Yue FY, Kovacs CM, Dimayuga RC, et al. Preferential apoptosis of HIV-1-specific CD4 T cells. J Immunol 2005;174:2196-204.

17. Carreiro DM. Terapia nutricional no estresse oxidativo. In: Silva SMCS, Mura JDP eds. Tratado de alimentação, nutrição e dietoterapia. São Paulo: Roca, 2007:611-22.

18. Mehta S, Fawzi WW. Micronutrient supplementation as adjunct treatment for HIV-infected patients. Clin Infect Dis 2010;50:1661-3.

19. Allard JP, Aghdassi E, Chau J, et al. Effects of vitamin E and C supplementation on oxidative stress and viral load in HIV-infected subjects. Aids 1998;12:1653-59.

20. Batterham M, Gold J, Naidoo D, et al. A preliminary open label dose comparison using an antioxidant regimen to determine the effect on viral load and oxidative stress in men with HIV/AIDS. Eur J Clin Nutr 2001;55:107-14. nitrogen species (52-54), reflecting on the viral load (19) and on the number of CD4+ and CD8+ cells in subjects (21).

Therefore, our data combined with the data in literature suggest that nutritional intervention, such as A sylvaticus supplementation, can be considered an effective contribution to HIV infection treatment associated with HAART, reducing OS and improving antioxidant capacity in HIV patients. Nevertheless, further research is needed to better evaluate the effects of this supplementation on viral load, CD4+ and CD8+ T cell count, as well as on the quality of life of these subjects.

ACKNOWLEDGEMENTS: The authors thank Cogumelo do Sol Agaricus do Brasil Comércio, Importação e Exportação Ltda for the donation of A sylvaticus syrup, Nurse Carla Cepêda for technical assistance, Dr Michael Dean Green for language assistance, FAPESP and PROPESP/ UFPA for providing financial support (SP) and CAPES for providing a scholarship (MSF).

21. Djohan Y, Camara C, Mondé A, et al. Interest of antioxidants in the care of the patients infected by the HIV: The experience of long term administration of Alternanthera pungens herb tea. Ann Biol Clin 2009:67:563-8.

22. Singhal N, Austin J. A clinical review of micronutrients in HIV infection. J Int Assoc Physicians AIDS Care 2002;1:63-75.

23. Young T. Effects of micronutrient supplementation on morbidity and mortality among HIV-infected individuals - a summary of the evidence. S Afr Med J 2006;96:1062-4.

24. Wasser SP. Review of medicinal mushrooms advances: Good news from old allies. Herbal Gram 2002;56:28-33.

25. Fortes RC, Novaes MR, Recôva VL, Melo AL. Immunological, hematological, and glycemia effects of dietary supplementation with Agaricus sylvaticus on patients' colorectal cancer. Exp Biol Med 2009;234:53-62.

26. Ellertsen LK, Hetland G. An extract of the medicinal mushroom Agaricus blazei Murill can protect against allergy. Clin Mol Allergy 2009;7:6.

27. Percário S, Naufal AS, Gennari MS, Gennari JL. Antioxidant activity of edible blushing wood mushroom, Agaricus sylvaticus Schaeff. (Agaricomycetideae) in vitro. Int J Med Mushrooms 2009; 11:133-40.

28. Smiderle FR, Ruthes AC, Van Arkel J, et al. Polysaccharides from Agaricus bisporus and Agaricus brasiliensis show similarities in their structures and their immunomodulatory effects on human monocytic THP-1 cells. BMC Complement Altern Med 2011;11:58.

29. Gomes BAQ. Efeitos da suplementação com antioxidantes sobre as alterações oxidativas cerebral e pulmonar em malária murina. Master's Thesis (Tropical Diseases), Federal University of Para, Belém, Para - Brazil, 2011.

30. Silva LFD. Efeito da suplementação com antioxidantes sobre as alterações oxidativas e produção de interferon gama e fator de necrose tumoral alfa em tecido pulmonar de camundongos infectados por Plasmodium berghei. Master's Thesis (Biology of Infectious and Parasitary Agents), Federal University of Pará, Belém, Para - Brazil, 2011.

31. Percário S, Odorizzi VF, Souza DR, et al. Edible mushroom Agaricus sylvaticus can prevent the onset of atheroma plaques in hipercholesterolemic rabbits. Cell Mol Biol 2008;17:1055-61.

32. Kohn HI, Liversedge M. On a new aerobic metabolite whose production by brain is inhibited by apomorphine, emetine, ergotamine, epinephrine, and menadione. J Pharmacol Experiment Ther 1944;82:292-300.

33. Percário S, Vital AC, Jablonka F. Dosagem do Malondialdeído. Newslab 1994;2:46-50.

34. Miller N, Rice-Evans C, Davies M, Gopinathan V, Milner A. A novel method for measuring antioxidant capacity and its application to monitoring the antioxidant status in premature neonates. Clin Sci 1993;84:407-12.

35. Re R, Pellegrini R, Proteggente A, Pannala A, Yang M, Rice-Evans C. Antioxidant activity applying an improved ABTS radical cation decolorization assay. Free Rad Biol Med 1999;26:1231-7.

36. Blois SM. Antioxidant determinations by the use of a stable free radical. Nature 1958;181:1199-200. 
37. Brazil. Ministério da saúde. Conselho nacional de saúde. Regulamentação de pesquisas envolvendo seres humanos. Resolução n¹96/96. Brasília, DF, 1996.

38. Ayres M, Ayres Jr. BioEstat 5.0: Aplicações Estatísticas nas Áreas das Ciências Biológicas e Médicas. Brasília: CNPq; 2008:106.

39. Jareno EJ, Bosch-Morell F, Fernández-Delgado R, Donat J, Romero FJ. Serum malondialdehyde in HIV seropositive children. Free Radic Biol Med 1998;24:503-6.

40. Djinhi J, Tiahou G, Zirihi G, et al. Selenium deficiency and oxidative stress in asymptomatic HIV1-infected patients in Côte D'ivoire. Bull Soc Pathol Exot 2009;102:11-13.

41. Blond D, Raoul H, Le Grand R, Dormont D. Nitric oxide synthesis enhances human immunodeficiency virus replication in primary human macrophages. J Virol 2000;74:8904-12.

42. Chiappini E, Galli L, Azzari C, De Martino M. Nitric oxide in HIV-1 perinatally infected children treated with highly active antiretroviral therapy. Lancet Infect Dis 2003;3:128-9.

43. Chanarat N, Chanarat P, Suttajit M, Chiewsilp D. Total antioxidant capacity in plasma of HIV-infected patients. J Med Assoc Thai 1997;80:116-20.

44. Coaccioli S, Crapa G, Fantera M, et al. Oxidant/antioxidant status in patients with chronic HIV infection. Clin Ter 2010;1:55-8.

45. Delmas-Beauvieux MC, Peuchant E, Couchouron A, et al. The enzymatic antioxidant system in blood and glutathione status in human immunodeficiency virus (HIV)-infected patients: Effects of supplementation with selenium or $\beta$-carotene. Am J Clin Nutr $1996 ; 64: 101-7$.
46. Choi J, Liu RM, Kundu RK, et al. Molecular mechanism of decreased glutathione content in human immunodeficiency virus type 1 tat-transgenic mice. J Biol Chem 2000;275:3693-8.

47. Favier A, Sappey C, Leclerc P, Faure P, Micoud M. Antioxidant status and lipid peroxidation in patients infected with HIV. Chem Biol Interact 1994;91:165-80.

48. Baum MK. Role of micronutrients in HIV-infected intravenous drug users. J Acquir Imm Defic Syndr 2000;25:S49-52.

49. Ambrus JL, Ambrus JL Jr. Nutrition and acquired immunodeficiency syndrome. Exp Biol Med 2004;229:865.

50. Buys H, Hendricks M, Eley B, Hussey G. The role of nutrition and micronutrients in pediatric HIV infection. South Afr Dent J 2002;57:454-6.

51. Baum MK, Shor-Posner G. Micronutrient status in relationship to mortality in HIV-1 disease. Nutr Rev 1998;56:135-9.

52. Arendt BM, Boetzer AM, Lemoch $\mathrm{H}$, et al. Plasma antioxidant capacity of HIV-seropositive and healthy subjects during long-term ingestion of fruit juices or a fruit-vegetable-concentrate containing antioxidant polyphenols. Eur J Clin Nutr 2001;55:786-92.

53. Jaruga P, Jaruga B, Gackowski D, et al. Supplementation with antioxidant vitamins prevents oxidative modification of DNA in lymphocytes of HIV-infected patients. Free Radic Biol Med 2002;32:414-20.

54. Mcdermid JM, Lalonde RG, Gray-Donald K, Baruchel S, Kubow S. Associations between dietary antioxidant intake and oxidative stress in HIV-seropositive and HIV-seronegative men and women. Acquir Immune Defic Syndr 2002;29:158-64. 


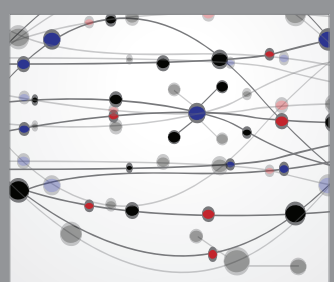

The Scientific World Journal
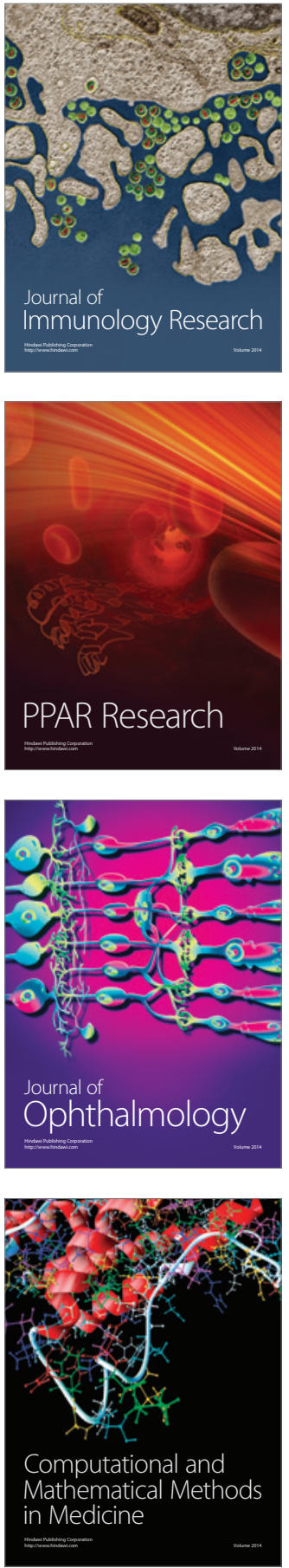

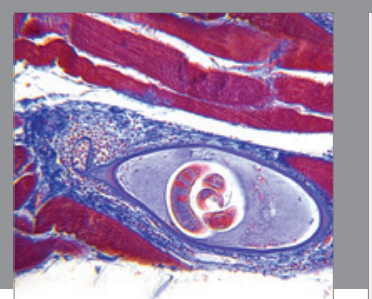

Gastroenterology Research and Practice

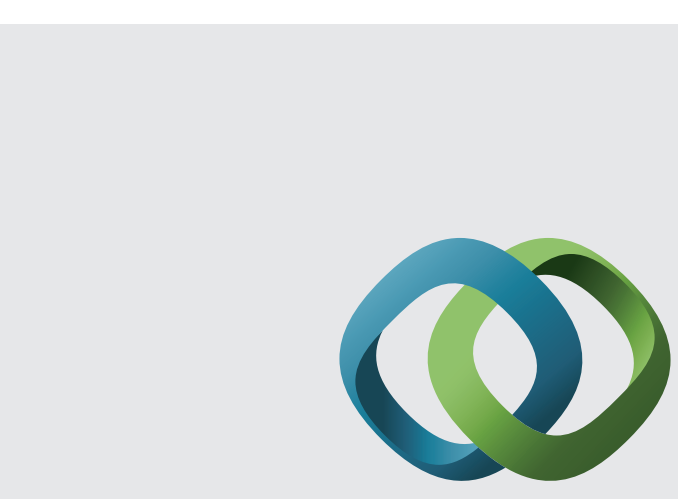

\section{Hindawi}

Submit your manuscripts at

http://www.hindawi.com
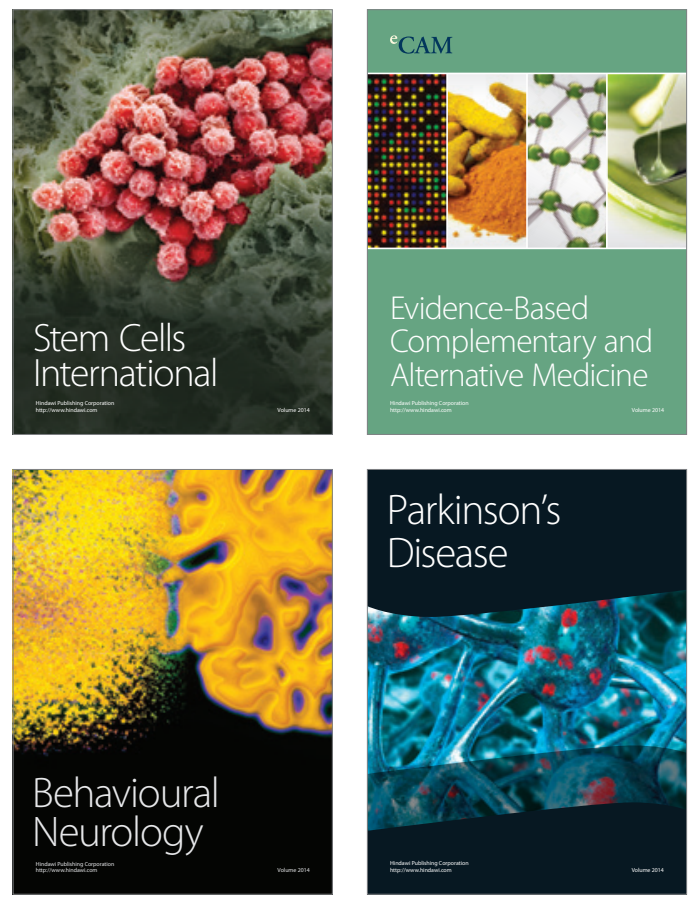
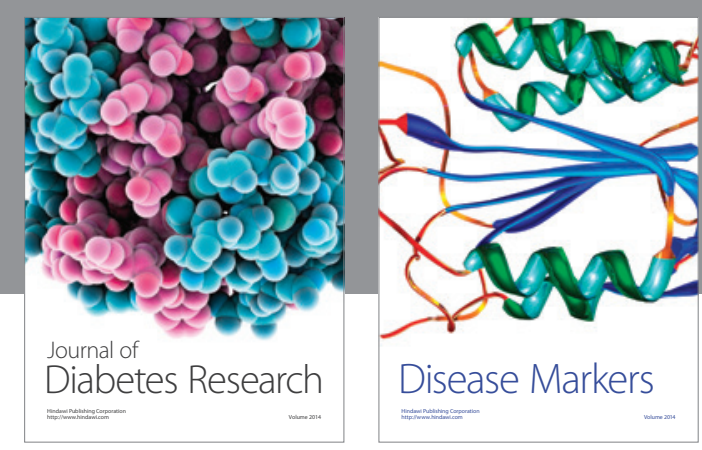

Disease Markers
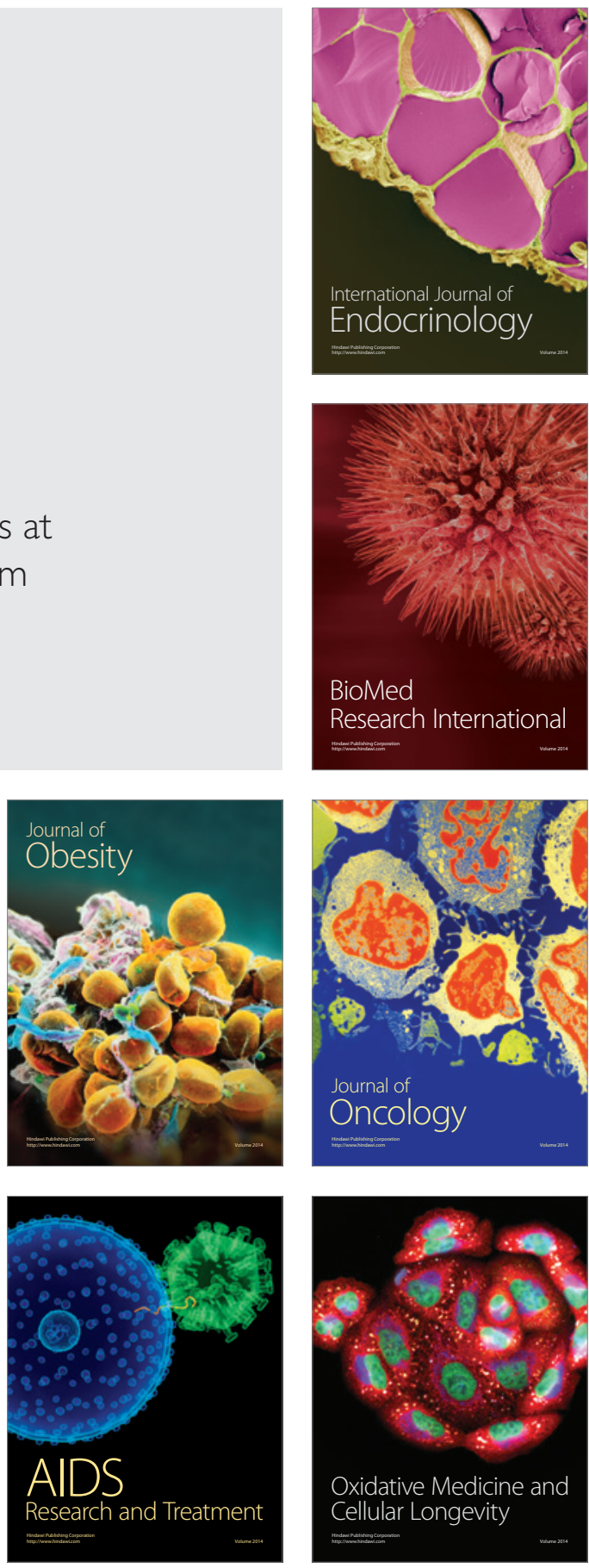